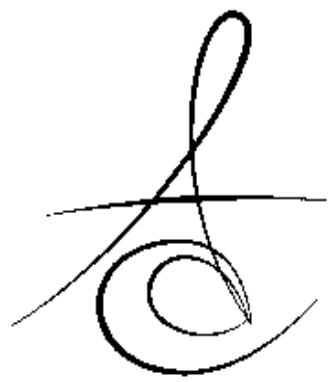

\title{
CAD-CAM VE LAZER SİNTERLEME TEKNİKLERİ İLE ÜRETİLEN METAL ALT YAPILI SERAMİK RESTORASYONLARDA MARJİNAL UYUM
}

\section{MARGINAL ADAPTATION OF METAL-CERAMIC FIXED PARTIAL DENTURES FABRICATED BY CAD-CAM AND LASER SINTERING}

\author{
Arş. Gör. Dt. M. Abdullah KELEŞ* $\quad$ Prof Dr. Ş. Begüm TÜRKER*
}

\author{
Makale Kodu/Article code: 2793 \\ Makale Gönderilme tarihi: 131.04 .2016 \\ Kabul Tarihi: 29.06.2016
}

\section{öz}

Diğer birçok endüstri alanında olduğu gibi dental teknoloji alanında da üretim safhaları gittikçe artan bir oranda makineleşmeye başlamıştır. Bilgisayar teknolojisindeki gelişmeler ile bireysel parçaların uygun maliyetli üretimi sağlanmaktadır. Son yıllarda bilgisayar yardımı ile üretilmiş restorasyonların kullanımı yaygınlaşmıştır. Restorasyonların kalitesi ve klinik başarısı değerlendirilirken marjinal adaptasyon temel belirleyici özelliktir. Bu çalışmanın amacı, metal seramik restorasyonların alt yapının hazırlanmasında kullanılan CAD-CAM ve Lazer sinterleme sistemlerinin avantaj ve dezavantajları, sınıflandırılması ve bu sistemlerde kullanılan materyaller ve sistemi oluşturan ekipmanlar hakkında ve ilgili sistemlerle yapılmış marjinal uyum çalışmaları ile ilgili bilgi vermektir.

Anahtar Kelimeler: CAD-CAM, lazer sinterleme, marjinal uyum

\section{GİRİŞ}

Diğer endüstri alanlarında olduğu gibi diş hekimliği teknolojisinde de üretim aşamaları gittikçe makineleşmeye başlamıştır. Diş hekimliğinde laboratuvar masrafları tedavi ve planlamada oldukça önemli bir faktördür. Dijital diş hekimliği piyasadaki rekabetçi üretim için uygun imkanlar sunmaktadır. Bilgisayar teknolojisindeki gelişmeler ile daha seri ve daha ekonomik üretim gündeme gelmiştir ve günümüzde bilgisayar yardımı ile üretilmiş restorasyonların kullanımı yaygınlaşmıştır ${ }^{1}$.

CAD/CAM Sistemi (computer aided design/computer aided manufacturing)

CAD/CAM sistemlerinin geliştirilmesi ilk olarak 1970'li yıllarda Dr. Duret tarafından Sopha sisteminin

\section{ABSTRACT}

As in many other industries, production stages are increasingly becoming automated in dental technology. Advances in computer technology now enable cost-effective production of individual pieces. Dental restorations produced with computer assistance have become more common in recent years. The marginal adaptation is the most important factor when the quality and clinical success of a restoration was evaluated. The aim of this article was to give an idea about the CAD/CAM and laser sintering technologies and systems available for dentistry today. The advantages, disadvantages, classification and equipment's of these systems and the studies about the marginal adaptation will discussed too.

Keywords: CAD-CAM, laser sintering , marginal adaptation

geliştirilmesi ile başlamıştır. Daha sonra Dr. Moermann ve Dr. Andersson sırasıyla CEREC ve Procera sistemini geliştirmişlerdir ${ }^{2}$. CAD, bilgisayar destekli tasarımın (computer aided design) kısaltmasıdır, CAM ise bilgisayar destekli üretimin (computer aided manufacturing) kısaltmasıdır. CAD/CAM terimi üretim metodu ile ilgili bilgi vermemektedir. CAD/CAM teknolojisinin: yeni, sorunsuz ve kontrollü materyal üretimi; teknik hassasiyet, kalite ve verimliliğin arttırıması ve standart zincir üretim için veri saklanması; planlamanın geliştirilmesi gibi oldukça önemli avantajları vardır. Bu teknoloji ile ölçü alma, alçı dökme ve mum modelaj üretimi gibi aşamalarına duyulan ihtiyaç azalır. Ayrıca hızlı bir şekilde yapılabilen tasarımın gerektiğinde değiştirilebilmesi ve çoğaltılabilmesi gibi avantajları da vardır.

\footnotetext{
* Marmara Üniversitesi Dişhekimliği Fakültesi, Protetik Diş Tedavisi Ana Bilim Dalı, İstanbul
}

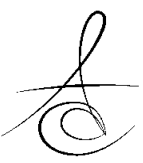


CAD/CAM teknolojisinde veriler bilgisayar yardımı ile toplanarak tasarım ve üretimde kullanılır. Bilgisayar teknolojilerindeki gelişmelerle yeni üretim metotları sağlanabilir, yeni tedavi yöntemleri geliştirilebilir ${ }^{1}$.

Bilgisayar destekli tasarım ve bilgisayar destekli üretim; konvansiyonel yöntemleri ortadan kaldırır, restorasyonu klinikte/hasta başında üretebilmeyi sağlar, çok iyi bir estetik sağlar ve restorasyonun kalitesini arttırır ${ }^{3}$.

\section{CAD/CAM Sistemlerinin Avantaj ve Dezavantajları}

Teknolojinin her geçen gün gelişmesi ve bu gelişmelerin diş hekimliğine de yansımasıyla CAD/CAM sistemlerinin mevcut avantajları artmakta, dezavantajları ise gün geçtikçe azalmaktadır.

\section{Avantajları:}

Üretim için gereken zamanın daha az olması, laboratuvar işlemlerinin ortadan kalkması, kullanılan materyallerin yüksek kalitede olması, restorasyonları yüksek kalite ve hassasiyetle üretilebilmesi ve bu kalitenin sürekliliği, tabaka kalınlığı/çapı, prepare edilen dişin şekli gibi değişkenlerin kontrolündeki kolaylık CAD/CAM sistemlerinin avantajlarıdır ${ }^{4}$.

\section{Dezavantajları:}

Kullanılan bazı sistemlerin uzman bir operatör gerektirmesi, monokromatik prefabrike blok kulanımında tam seramik sistemlerde yaşanan renk sorunu, kullanılan cihazların maliyetinin yüksek olması CAD/ CAM sistemlerinin dezavantajları olarak sıralanabilir ${ }^{4}$.

\section{CAD/CAM Sistemlerinin Sınıflandırılması}

Diş hekimliğinde, CAD/CAM sistemi bileşenlerinin bulunduğu yere göre üç farklı şekilde sınıflandırılır ${ }^{1}$ :

1. Hasta başında üretim (chairside concept): Laboratuvar işlemlerine gerek olmaksızın, klinikte, preparasyonun yapıldığı seansta restorasyon üretilir. Ağız içi kamera kullanılarak konvansiyonel ölçü alma işlemleri elimine edilir. Zaman kazanc sağlanır ve hastaya tek seansta restorasyon teslim edilir.

\section{Laboratuvar üretimi (labside concept):} $\mathrm{Bu}$ yöntemde laboratuvar işlemi gerekmektedir. Diş hekimi aldığı ölçüyü ana modelin üretilmesi için laboratuvara gönderir. Sonra tarayıcı yardımıyla ana model üzerinde üç boyutlu görüntü kaydedilir. Tasarım işleminden sonra veriler aşındırma cihazına gönderilir.
Daha sonra altyapının uyumu ana model üzerinde kontrol edilir ve gerekli ise düzeltmeler yapılır. En son aşamada diş teknisyeni tarafından seramik uygulaması gerçekleştirilir ${ }^{5}$.

3. Merkezileştirilmiş üretim (centralised concept): $\mathrm{Bu}$ üretim şeklinde bilgisayar yardımı ile dental restorasyonun üretimi aşındırma merkezinde gerçekleşmektedir. Laboratuvarda üretilen veriler, CAD/CAM cihazı ile üretimin yapılması amacıyla internet vasıtası ile bağlantı kurulabilen bir üretim merkezine gönderilir. Restorasyon üretildikten sonra sorumlu laboratuvara ulaştırılır. Ana model üzerindeki son kontroller yine laboratuvarda gerçekleştirilir. Özet olarak bu yöntemde üretimin 1 . ve 2 . basamakları laboratuvarda, 3. basamak ise üretim merkezinde gerçekleştirilmektedir 6 .

CAD/CAM sistemlerini açık ve kapalı sistemler olarak da sınıflandırmak mümkündür;

I- Açık sistemler: Bu sistemde tasarımın üç boyutlu bilgisi yazılım kısmından donanım kısmına gönderilir. Açık sistemler, farklı donanımlar arasında ve farklı üretim merkezleri arasında seçme şansı sunar.

II- Kapalı sistemler: Kapalı sistemlerde; tarayıcı, yazılım ve donanım üniteleri bir arada, aynı yerde bulunmaktadır. CAM sistemleri arasında seçim yapılmasına imkan sağlamaz ${ }^{7}$.

\section{CAD/CAM Sistemlerinde Kullanılan Materyaller \\ CAD/CAM sistemlerinde farklı materyaller} kullanılabilmektedir.

1. Metaller: Diş hekimliğinde kullanılan aşındırma cihazlarında; titanyum, titanyum alaşımları, kobalt-krom alaşımları kullanılabilmektedir. Yüksek maliyetinden dolayı değerli metal alaşımlarının kullanılması tercih edilmemektedir. Örneğin; Everest Bio T-Blank (KaVo, saf titanyum).

2. Rezin materyaller: Rezin materyaller kullanılarak geçici kuron ve köprü protezlerinin altyapıları veya tam anatomikleri üretilebilmektedir. Piyasada bulunan rezin materyallere örnek olarak Cercon base cast (DeguDent) ve Everest C-Cast(Kavo) verilebilir.

3. Silika bazlı seramikler: İnley, onley, vener, parsiyel kuron ve tam kuronların üretiminde kullanılabilmektedir. Piyasada monokromatik ve çok renkli bloklar olarak bulunmaktadır, örneğin; IPS Empress CAD Multi (IvoclarVivadent) çok renkli, IPS 
e.max CAD Multi (IvoclarVivadent) monokromatik bloklardır.

4. Infiltrasyon seramikleri: Aşındırılabilen infiltrasyon seramik blokları poröz yapıda hazırlanır daha sonra cam infiltre edilir. Piyasada Vita In-Ceram Alumina (Al2O3), Vita In-Ceram Zirconia (70\% Al2O3, $30 \%$ ZrO2) ve VITA In- Ceram Spinell (MgAl2O4) olarak bulunmaktadır.

5. Okside yüksek performans seramikleri: Günümüzde CAD/CAM sistemleri için hazırlanmış aluminyum oksit ve zirkonyum oksit bloklar bulunmaktadır. Piyasada bulunan aluminyum oksit bloklarına örnek olarak In-Ceram AL Block (Vita) ve inCoris Al (Sirona) verilebilir. Zirkonyum oksit bloklarına ise örnek olarak; Lava Frame (3M ESPE), Cercon Smart Ceramics (DeguDent), Everest $\mathrm{ZS}$ und $\mathrm{ZH}$ (KaVo), inCoris $\mathrm{Zr}$ (Sirona), In-Ceram YZ (Vita) ve zerion (etkon)'u verilebilir ${ }^{1}$

\section{CAD/CAM Sistemlerini Oluşturan Ekipmanlar}

\section{Tarayıcı}

Üç boyutlu diş ve çene yapılarını tarayarak dijital veri olarak kayıt eden kısımdır (Beuer ve ark., 2008). Ağız içi, optik ve mekanik olmak üzere üç farklı tarayıcı vardır?;

Ağız içi tarayıcı: Ağız boşluğundaki prepare edilen diş ve çevresindeki yapıların görüntülerini dijital olarak kaydeden tarayıcıdır ${ }^{7}$.

Optik tarayıcı: Işık kaynağı olarak beyaz ışık veya lazer ışığı kullanılarak görüntüleme yapan tarayıcıdır ${ }^{4}$.

Mekanik tarayıcı: Ana model üzerinden yakut bir küre yardımıyla mekanik tarama yapan tarayıcıdır. Yüksek doğrulukta tarama yapmaya izin verir, hata payı oldukça düşüktür ${ }^{8}$.

\section{Yazılım}

Farklı çeşitlerde restorasyon tasarımının ve planlamasının üç boyutlu olarak yapılabileceği kısımdır. Yazılımda, kuron ve köprü restorasyonların altyapı tasarımı gerçekleştirilebileceği gibi, tam anatomik kuron, parsiyel kuron, inley ve onley ayaklı köprü tasarımları da yapılabilmektedir ${ }^{9}$.

\section{Donanım}

CAD/CAM sistemlerinde metal altyapı üretimi, $\mathrm{Co}-\mathrm{Cr}$ metal bloğun aşındırıması ve metal tozlarının lazer sinterleme vasıtasıyla birbirine tabaka tabaka kaynaştırılması şeklinde 2 farklı yolla yapılabilir ${ }^{10}$
Aşındırma cihazlarının yazılım kısmında üretilen verilerin aktarıldığı donanım kısmı freze ve aşındırma ünitelerinden meydana gelir. Burada işlem, materyal bloklarının frezelenmesi yoluyla olur ${ }^{11}$. Donanım cihazları aşındırma eksenlerinin sayısına göre 3 eksenli, 4 eksenli ve 5 eksenli aşındırma cihazları olmak üzere 3'e ayrıır. Aşındırma, kuru ve ıslak aşındırma olarak iki farklı şekilde gerçekleştirilebilir. Metaller ve cam seramikler ıslak aşındırma işlemi ile aşındırıır. Islak aşındırma esnasında kullanılan elmas ya da karbid kesici uçlara materyalin aşırı ısınmasını engellemek amacıyla soğuk bir sprey uygulanır ${ }^{1}$.

Lazer sinterleme cihazlarının donanım kısmında toz malzeme yatağı bulunur. Toz malzemeye uygulanan lazer ışı̆ı ile tabaka tabaka ergitme gerçekleştirilir ve üretim gerçekleştirilir.

\section{Lazer Sinterleme ve Doğrudan Metal Lazer Sinterleme (DMLS)}

Lazer sinterleme tekniği hızlı direkt imalat sistemlerinin gelişmesi ile ortaya çıkmıştır. Hızlı direkt imalat sistemlerinde üretilen son ürün bir prototip ise işleme "Hızı Prototip Üretim" adı verilir. Hızı prototip cihazları; Toz Bağlama, Işıkla Kür, Tabaka Yığma ve Harç Yığma olmak üzere dört gruba ayrılır. Hızlı prototipleme teknolojisi ile üç boyutlu parçalar konvansiyonel aletlere gerek duymaksızın direkt olarak bilgisayar tasarımından üretilebilmektedir. Konvansiyonel yöntemlerle üretilemeyen parçalar çok kısa süre içerisinde hızlı prototipleme ile üretilebilmektedir. Hızlı prototipleme yöntemleriyle daha önce plastik materyaller kullanılırken teknolojide gelişmeler kaydedilmesi ile birlikte günümüzde metaller kullanılabilmektedir ${ }^{12}$.

1971 yılında Pierre Ciraud, lazer ışını kullanılarak metal tozları ergiterek birbirine kaynaştırma ve katı metal parçalar oluşturma fikrini ortaya atmıştır. Ancak, o dönemdeki bilgisayar teknolojileri bu fikrin hayata geçirilmesine izin vermemiştir. 1984 yılında Chuck Hull, hızlı prototiplemenin ticarileşmesi adına 3D Systems firmasını kurmuştur. Chuck Hull, detaylı olarak üç boyutlu tabaka tabaka üretim yapacak bir cihazın çalışma metodunu açıklamış ve bu alanda alınan ilk patentin sahibi olmuştur. Chuck Hull açıkladığı sistemde yapı malzemesi olarak sıvı reçine tercih etmiş fakat daha sonra sıvılardan başka materyaller de kullanılabileceğinin farkına vararak sistemi stereolitografi olarak adlandırmıştır. Günümüzde tabakalı üretimde kullanımakta olan, katı materyallerin yüzeylerini tanımlayan 
dosya formatı STL'nin patent başvurusunu yine Chuck Hull yapmıştır.

Materyallere bilgisayar yardımı ile foton veya ISı uygulanarak şekil vermek hızlı prototip teknolojilerinin temelini teşkil eder. Bu sistemleri kullanarak bilgisayarda hazırlanmış üç boyutlu tasarımdan hedef parçayı üretebilmek mümkündür. Ürünün kısa zamanda ve yüksek verimle üretilmesi, gelişen ve gün geçtikçe daha rekabetçi bir hal alan dental sektörde büyük avantaj sağlamaktadır. Metal tozlarından direkt olarak esas parçanın üretimine imkan sağlayan Seçici Lazer Sinterleme (SLS) ve Seçici Lazer Ergitme (SLE) sistemlerinin gelişimi prototip anlayışını kırması yönüyle üretim sektörü açısından büyük önem taşımaktadır ${ }^{13}$.

Paslanmaz çelik, titanyum alaşımı, nikel bazlı alaşımlar, kobalt bazlı alaşımlar ve aluminyum materyalleri kullanılarak; seçici lazer sinterleme, seçici lazer ergitme, lazer mikrosinterleme ve üç boyutlu lazer kaplama yöntemleriyle lazer uygulanır ve metal parçalar üretilir. Üretilen metal parçalar otomotiv sektöründe, uzay sanayisinde ve biyomedikal alanda kullanılabilii ${ }^{14}$.

Herhangi bir toz malzeme yatağının yüzeyine lazer veya farklı bir ışık uygulanması yöntemiyle katman katman ergitilerek katı parça üretilmesine "lazer sinterleme" adı verilir. Bu yöntemde uygun metal tozları kullanımı ile metal parça üretimine verilen ad ise "Doğrudan Metal Lazer Sinterleme (DMLS)"dir. 1986'da Carl Deckard, toz malzeme kullanarak bir çalışma gerçekleştirmiştir ve yöntemine Seçici Lazer Sinterleme (SLS) adını vermiştir. 1987 yılında Michael Feygin, lazer kullanarak $0.002-0.02$ inç kalınlığındaki metal toz tabakasını ısııcı bir silindir yardımı ile kontrollü basınç altında sıkıştırma ve daha sonra tabakayı lazer ile katman kesitine uygun olarak tarama prensibine dayalı yeni bir fikir geliştirmiş, 1989 yllında Nyrhila, $100 \mathrm{~m}$ kalınlığındaki bronz-nikel bazlı toz metali bir DMLS cihazı olan EOSINT M 250 cihazında kullanmıştır ve daha önce üretilemeyen dayanıkı parçaların yüksek kalitede üretimine önayak olmuştur. DMLS yöntemi, EOS firması tarafından Almanya'da geliştirilmiştir ve 1995 ylından itibaren EOSINT M 250 lazer sinterleme makinası ile birlikte ticari olarak piyasada yer almaktadır.

Seçici Lazer Sinterleme (SLS)/ Seçici Lazer Ergitme (SLE) (Isıtarak Toz Bağlama) yönteminde ISI altında birbirine kaynaşan bir inşa materyali tozu kullanıı.ır. İnce bir tabaka şeklinde yayılan toz yüzeyinde saptanan bölgeler lazer ile taranarak bu bölgelerdeki tozun sinterlenerek komşu toz taneleri ile kaynaşması sağlanır. Toz tanelerinin birbirine kısmen ve/veya tamamen kaynaşması sağlandıktan sonra, üretim ünitesinin tabanında bulunan düzlem, bir katman kalınlığı aşağı yönde hareket eder. Bu işlem ana parça üretilinceye kadar defalarca tekrarlanır. Üretim işlemi sonrasında serbest tozlar vakum veya fırça yardımı ile üretim platformundan uzaklaştırıır. Oksidasyonun ortadan kaldırıması için genelde nitrojen veya argon gaz ortamında sinterleme ve ergitme gerçekleştirilir. İşlemin hızını ve verimliliğini arttırmak için üretim yüzeyi ısıtıcılarla ısıtııır ${ }^{15}$.

SLS işleminde, toz partikülleri arasında bölgesel ergitme meydana gelirken, SLE işleminde ise toz malzemede tam ergitme meydana gelir. Yöntemde, düşük ergime derecesine sahip tozlar, tek bileşenli ve alaşımlı tozlar kullanılmaktadır. Sinterlemede düşük ergime noktasına sahip metaller kullanıldığında tam erime mümkün olmaktadır. Ergitmede ise üretilen parçaların yoğunluğu yüksektir. SLS yönteminde; metal ve seramik tozlarının yanında, plastik, mum, naylon ve polikarbonatlar da kullanılabilmektedir. SLS yöntemi; oldukça verimli bir yöntemdir, zaman kazancı sağlamaktadır, üretim kolay ve hassas bir şekilde yapılabilmekte ve üretilen model için çok az bitirme işlemine intiyaç duyulmaktadır ${ }^{15}$.

\section{Lazer Sinterlemede İşlem Sırası}

Data hazırlanması: Önce CAD programında üç boyutlu model tasarımı ve planlaması yapılır. Daha sonra ilgili CAD dosyasının formatı STL formatına çevrilerek kaydı gerçekleştirilir. 3D Systems adı ıirma tarafından geliştirilen STL formatı hızlı imalat yapan cihazlarda standarttır ve imalatın daha basit ve kolay uygulanabilir olmasını sağlar. STL dosyası, üçgenler yardımıyla taranan parçanın dış yüzeyini meydana getirir. ASCII ve ikili format olmak üzere iki farklı STL formatı bulunmaktadır. Bunlardan ikili format daha az yer kaplar fakat okunurluğu ASCII formatına göre daha kötüdür. Avantajlarının yanında STL formatının bazı dezavantajları vardır. STL formatında bazı geometrik kusurlarla karşısaşımaktadır. Bir STL dosyası orijinal CAD dosyasından daha fazla yer kaplayabilmektedir ve büyük STL dosyalarının dilimlenmesi çok uzun zaman alabilmektedir. Üretim işleminin yavaşlamasına neden olan hatalar için onarım yazılımına gerek duyulmaktadır. Bazı CAD sistemlerinde STL formatıyla uyumsuzluk sorunu ile karşılaşılmaktadır. STL forma- 
tıyla kayıt edilen dosya, üretim cihazının yazılımına gönderilir. SLS ve SLE cihazları tarafından üretimi yapılacak model yatay olarak dilimlenerek üretim işlemine hazır hale getirilir ${ }^{15,16}$.

Üretim Aşaması: Üretilecek parça için hangi materyalin kullanılacağı saptanır. Üretim cihazına uygun tane boyutuna sahip metal tozu seçilmelidir. Piyasada üretim cihazları için özel olarak üretilmiş metal tozları bulunmaktadır. Seçilen metal tozu üretim cihazının haznesine yerleştirilir ve üretim sürecine başlanır. Modelin üretilmesinde parça üzerindeki ana unsurlar üretim sırasında desteklenmeli ve çevresindeki boşluğa çökmesi önlenmelidir: Bu amaçla, modeldeki ana unsur olmayan boşluk bölgeler destek yapılar ile hazırlanır. Üretim tamamlandıktan sonra bu destek yapılar parça yüzeyinden uzaklaştırılarak temizlenir. Sütunlu destek ve çevreleyici destek olmak üzere iki farklı destek yapı kullanılır. Sütunlu destek; sütunlar şeklinde hazırlanır. Farklı bir materyal kullanılabileceği gibi ana üretim materyali de kullanılabilir. Üretim aşamasından sonra kimyasal olarak, el yardımıyla kırılarak veya ısı ile uzaklaştırılabilir. Çevreleyici destek; üretilecek ana parça haricindeki boşluğa kimyasal madde doldurulur. Üretim işlemi sonrasında bu destek yapı kimyasal sıvılar yardımıyla uzaklaştırııı ${ }^{13,15}$.

Yüzey İşlemleri: Üretilen prototip/son ürün yüzeyinin son kontrolü yapılır. Porözlü yüzey gibi yapısal bir hata olup olmadığı saptanır. Uygun tesviye işlemleri yapılarak ürünün son işlemleri tamamlanır.

\section{Eosint Teknolojisi}

EOS (EOS M270) (EOS, Münih, Almanya) firması tarafından SLS (Seçici Lazer Sinterleme) olarak bilinen üretim teknolojisinin patentlenmiş adıdır. Uygulamaya bağlı olarak çelik, alüminyum ve titanyum alaşımlar, nikel bazlı alaşımlar, kobalt-krom alaşımları kullanıl- maktadır. EOSINT $R$, metal tozunun 200W gücündeki fiber lazer teknolojisi ile bölgesel olarak eritilmek sure- tiyle gerçekleşen bir işlemdir. Lazer ışını ile taranarak parçanın yüzeyleri meydana getirilir. Soğutmanın ar- dından malzeme sertleşir. Üretim alanının (250mm x 250mm x 215mm) aşağı doğru ilerlemesiyle yeni katmanlar için yeniden toz serperek ve eritme yapılarak, tabaka tabaka kalıp üretimi yapılır, katman aralığı 20-100 $\mu m^{\prime}$ dir. Üretim hızı 2-20 mm3/s' dir.

\section{CAD-CAM ve DMLS Metoduyla Üretilen Metal Alt Yapılarla İlgili Marjinal Uyum Çalışmaları}

Literatürde; lazer sinterleme, CAD/CAM metal frezeleme ve konvansiyonel mum uçurma tekniği ile üretilen metal altyapıların marjinal uyumlarını karşılaştıran çalışmalarda çoğunlukla tek üyeli restorasyonlar kullanılmıştır. 3 üyeli restorasyonlarda sınırlı sayıda çalışma yapılmıştır.

Sundar ve ark. ${ }^{17}$, in vitro çalışmalarında konvansiyonel mum uçurma tekniği ile üretilen $\mathrm{Co}-\mathrm{Cr}$ altyapılı tek kuronların marjinal uyum değerlerini metal lazer sinterleme ile üretilen $\mathrm{Ni}-\mathrm{Cr}$ altyapılı tek kuronların marjinal uyum değerleri ile karşılaştırmışlardır. Porselen fırınlama işlemi öncesi; konvansiyonel $\mathrm{Ni}-\mathrm{Cr}$ grubunda 66,24 $\mu \mathrm{m}$, lazer sinterleme Co-Cr grubunda 56,26 um ortalama marjinal aralık değerleri bulunmuştur. Porselen fırınlama işlemi sonrası; konvansiyonel $\mathrm{Ni}-\mathrm{Cr}$ grubunda $70,83 \mu \mathrm{m}$, lazer sinterleme Co$\mathrm{Cr}$ grubunda 53,63 $\mu \mathrm{m}$ ortalama marjinal aralık değerleri bulunmuştur. Porselen fırınlama işlemi öncesinde ve sonrasında metal lazer sinterleme ile üretilen altyapıların, konvansiyonel mum uçurma yöntemiyle üretilen altyapılara göre daha iyi marjinal uyum değerlerine sahip olduğu görülmüştür. Porselen fırınlama işleminin metal lazer sinterleme ile üretilmiş altyapıların marjinal aralık değerlerini düşürdüğü fakat bu düşüşün istatistiksel olarak anlamlı olmadığını bildirmişlerdir.

Shokry ve ark. ${ }^{18}$, yaptıkları in vitro çalışmada titanyum ve $\mathrm{Ni}-\mathrm{Cr}$ tek kuron altyapılarının porselen fırınlama işlemi öncesi, opak uygulaması ve dentin uygulaması sonrasında marjinal uyumlarını değerlendirmişler ve porselen fırınlama işleminin marjinal uyumu etkilediğini rapor etmişlerdir. Çalışmada, Everest sistemi kullanılarak saf titanyumun frezelenmesi ile üretilen altyapıların porselen fırınlama işlemi öncesi, opak uygulaması sonrası ve dentin uygulaması sonrasında ortalama marjinal aralık değerleri sırasıyla; 24,1 $\mu \mathrm{m}, 32,3 \mu \mathrm{m}$ ve 35,6 $\mu \mathrm{m}$ 'dır. Konvansiyonel mum uçurma tekniği kullanılarak saf titanyumundan üretilen altyapıların porselen fırınlama işlemi öncesi, opak uygulaması sonrası ve dentin uygulaması sonrasında ortalama marjinal aralık değerleri sırasıyla; 81,5 $\mu \mathrm{m}$, $83,8 \mu \mathrm{m}$ ve $83,7 \mu \mathrm{m}$ 'dir. Konvansiyonel mum uçurma tekniği kullanılarak Ti-6Al-7Nb alaşımından üretilen altyapıların porselen fırınlama işlemi öncesi, opak uygulaması sonrası ve dentin uygulaması sonrasında 
ortalama marjinal aralık değerleri sırasıyla; 47,3 $\mu \mathrm{m}$, 70,6 $\mu \mathrm{m}$ ve 70,6 $\mu \mathrm{m}$ 'dır. Konvansiyonel mum uçurma tekniği kullanılarak $\mathrm{Ni}-\mathrm{Cr}$ alaşımından üretilen altyapıların porselen fırınlama işlemi öncesi, opak uygulaması sonrası ve dentin uygulaması sonrasında ortalama marjinal aralık değerleri ise sırasıyla; 92,8 $\mu \mathrm{m}, 97,9$ $\mu \mathrm{m}$ ve $94 \mu \mathrm{m}^{\prime}$ dır. $\mathrm{Ni}-\mathrm{Cr}$ altyapılarda daha yüksek marjinal uyumsuzluk saptamışlardır.

Harish ve ark. ${ }^{19}$, konvansiyonel mum uçurma ve lazer sinterleme tekniği ile ürettikleri tek üyeli metal altyapıların marjinal ve internal uyumlarını inceledikleri in vitro çalışmalarında, konvansiyonel $\mathrm{Co}-\mathrm{Cr}$ grubu altyapıların ortalama marjinal aralık değerini $(176,57$ $\mu \mathrm{m})$, lazer sinterleme Co-Cr grubu altyapıların marjinal aralık değerinden $(102,1 \mu \mathrm{m})$ anlamlı derecede yüksek bulmuşlardır.

Xu ve ark. ${ }^{20}$, yaptıkları in vitro çalışmada seçici lazer ergitme ile üretilmiş $\mathrm{Co}-\mathrm{Cr}$ altyapıların marjinal uyumunu, döküm Co-Cr altyapıların marjinal uyumu ile karşılaştırdıkları çalışmalarında 36 kuronun marjinal aralık değerlerini ölçmüşler ve seçici lazer ergitme ile üretilen altyapıların marjinal aralık değerini $(102,86$ m), konvansiyonel mum uçurma yöntemiyle elde edilen altyapıların marjinal aralık değerinden $(170,19$ m) daha düşük bulmuşlardır.

Huang ve ark. ${ }^{21}$, yapmış oldukları in vivo çalışmada seçici lazer ergitme ile üretilmiş $\mathrm{Co}-\mathrm{Cr}$ altyapılı tek kuronların marjinal uyumunu, döküm $\mathrm{Co}-\mathrm{Cr}$ altyapılı tek kuronların ve döküm Au-Pt altyapılı tek kuronların marjinal uyumu ile karşılaştırmışlardır. Seçici lazer ergitme ile üretilmiş kuronların marjinal uyum değerlerinin (75.6 m), döküm Au-Pt altyapılı kuronların marjinal uyum değerlerine (76.8 m) yakın, döküm Co$\mathrm{Cr}$ altyapılı kuronların marjinal uyum değerlerinden (91.0 m) ise daha iyi olduğunu belirtmişlerdir.

Patil ve ark. ${ }^{22}$, yapmış oldukları in vitro çalışmada konvansiyonel mum uçurma tekniği ile üretilen $\mathrm{Ni}-\mathrm{Cr}$ ve titanyum altyapılı tek kuron restorasyonların porselen fırınlama işlemi öncesinde ve sonrasında marjinal uyumlarını incelemişler ve sonuç olarak her iki altyapıda da porselen fırınlama işlemi sonrası marjinal uyumsuzluğun arttığını belirtmişlerdir. Porselen fırınlama işlemi öncesinde; en yüksek ortalama marjinal aralık değeri kuronun marjinal kısmının metal ile

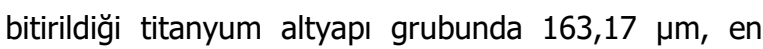
düşük ortalama marjinal aralık değeri kuronun marjinal kısmının metal ile bitirildiği $\mathrm{Ni}-\mathrm{Cr}$ altyapı grubunda 101,89 $\mu \mathrm{m}$ olarak bulunmuştur. Porselen fırınlama işlemi sonrasında; en yüksek ortalama marjinal aralık değeri kuronun marjinal kısmının metal ile bitirildiği titanyum altyapı grubunda 238,52 $\mu \mathrm{m}$, en düşük ortalama marjinal aralık değeri kuronun marjinal kısmının metal ile bitirildiği $\mathrm{Ni}-\mathrm{Cr}$ altyapı grubunda 129,10 um bulunmuştur.

Kim ve ark. ${ }^{23}$ yaptıkları in vitro çalışmada, lazer sinterleme (EOS M270) ve konvansiyonel mum uçurma tekniği ile ürettikleri $\mathrm{Co}-\mathrm{Cr}$ tek üyeli kuronların ortalama marjinal aralık değerlerini porselen fırınlama işlemi öncesinde lazer sinterleme grubunda $75 \mu \mathrm{m}$, konvansiyonel mum uçurma grubunda $62,3 \mu \mathrm{m}$; porselen fırınlama işlemi sonrasında lazer sinterleme grubunda 93,4 $\mu \mathrm{m}$, konvansiyonel mum uçurma grubunda 76,4 $\mu \mathrm{m}$ olarak bulmuşlardır ve porselen fırınlama işlemi sonrasında ortalama marjinal aralık değerlerinde anlamlı bir yükselme rapor etmişlerdir.

Park ve ark. ${ }^{24}$ in vitro çalışmalarında tek üyeli metal altyapıların ortalama marjinal aralık değerlerini; konvansiyonel mum uçurma grubunda 36,96 $\mu \mathrm{m}$, CAD/CAM metal frezeleme (Datron D5) grubunda $63,21 \mu \mathrm{m}$ ve doğrudan metal lazer sinterleme (EOSINT M270) grubunda 70,98 $\mu \mathrm{m}$ olarak bulmuşlardır.

Ucar ve ark. ${ }^{25}$ yaptıkları in vitro çalışmada, lazer sinterleme tekniği ile $\mathrm{Co}-\mathrm{Cr}$ ve konvansiyonel mum uçurma tekniği ile $\mathrm{Ni}-\mathrm{Cr}$ ve $\mathrm{Co}-\mathrm{Cr}$ tek üyeli metal altyapılar üretmişler ve internal uyum değerlendirmesi yapmışlardır. Ortalama internal aralık değerleri; lazer sinterleme grubunda $62,57 \mu \mathrm{m}$, konvansiyonel $\mathrm{Ni}-\mathrm{Cr}$ grubunda 58,21 $\mu \mathrm{m}$ ve konvansiyonel Co-Cr grubunda $50,55 \mu \mathrm{m}$ olarak bulunmuştur ${ }^{25}$. Değişik metal üretim teknikleri ile üretilen metal altyapıların ortalama marjinal aralık değerlerinin kullanılan sistemlere ve çalışmalara göre farklılık gösterdiği tespit edilmiştir.

Literatürdeki lazer sinterleme, CAD/CAM metal frezeleme ve konvansiyonel mum uçurma tekniği ile üretilen üç üyeli metal altyapıların marjinal uyumlarını karşılaştıran çalışmalara baktığımızda; Örtorp ve ark. ${ }^{26}$ in vitro çalışmalarında doğrudan metal lazer sinterleme, konvansiyonel mum uçurma, mum frezeleme ve metal frezeleme teknikleriyle ürettikleri üç üyeli $\mathrm{Co}-\mathrm{Cr}$ köprü altyapılarının marjinal uyumlarını incelemişlerdir. Ölçülen marjinal aralık değerleri; doğrudan metal lazer sinterleme grubunda: $84 \mu \mathrm{m}$, mum frezeleme grubunda: $117 \mu \mathrm{m}$, konvansiyonel mum uçurma grubunda: $133 \mu \mathrm{m}$ ve CAD/CAM metal frezeleme grubunda: $166 \mu \mathrm{m}$ olarak bulunmuştur. Elde edilen en

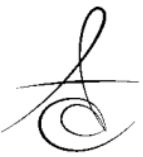


iyi marjinal aralık değerinin $84 \mu \mathrm{m}$ ile doğrudan metal lazer sinterleme grubuna ait olduğu görülmüştür.

Kim ve ark. ${ }^{27}$ lazer sinterleme tekniği (EOSINT M270, Co-Cr) ve konvansiyonel mum uçurma tekniği $(\mathrm{Ni}-\mathrm{Cr})$ ile ürettikleri üç üyeli sabit köprü protezi altyapılarının marjinal uyumunu inceledikleri in vitro çalışmalarında ortalama marjinal aralık değerlerini: doğrudan metal lazer sinterleme grubunda $130,6 \mu \mathrm{m}$ (premolar) ve 133,1 $\mu \mathrm{m}$ (molar), konvansiyonel mum uçurma grubunda $81,7 \mu \mathrm{m}$ (premolar) ve $81,8 \mu \mathrm{m}$ (molar) olarak ölçmüşlerdir.

Nesse ve ark. $^{28}$ konvansiyonel mum uçurma, CAD/CAM metal frezeleme ve seçici lazer ergitme teknikleri ile üç üyeli $\mathrm{Co}-\mathrm{Cr}$ altyapı elde ederek marjinal ve internal aralık ölçümü yaptıkları çalışmalarında, marjinal uyum incelemesini direkt izleme ve skorlama tekniği ile yapmışlar ve CAD/CAM metal frezeleme tekniğinin lazer sinterleme ve konvansiyonel mum uçurma tekniğine göre daha iyi sonuçlar verdiğini bildirmişlerdir.

\section{SONUÇ}

Günümüzde bilgisayar yardımı ile üretilmiş restorasyonların kullanımı yaygınlaşmışıtır. Bilgisayar teknolojisindeki gelişmeler ile daha seri ve daha ekonomik üretim gündeme gelmiştir. Bu teknoloji ile ölçü alma, alçı dökme ve mum modelaj üretimi gibi aşamalara duyulan intiyaç azalmış, hızlı bir şekilde yapılabilen tasarımın gerektiğinde değiştirilebilmesi ve çoğaltılabilmesi gibi avantajları da söz konusu olmuştur. CAD-CAM ve lazer sinterleme tekniği ile yapılan marjinal uyum çalsşmalarında porselen pişirme işlemleri öncesi ve sonrasında elde edilen marjinal aralık değerlerinin klinik olarak kabul edilebilir

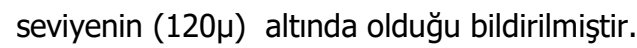

\section{Ş. Begüm Türker: ORCID ID: 0000-0003-2207-6535}

\section{KAYNAKLAR}

1. Beuer F, Schweiger J, Edelhoff D. Digital dentistry: an overview of recent developments for CAD/CAM generated restorations. $\mathrm{Br}$ Dent J 2008; 204: 505-11.

2. Miyazaki T, Hotta $Y$, Kunii J, Kuriyama $S$, Tamaki Y. A review of dental CAD/CAM: current status and future perspectives from 20 years of experience. Dent Mater J 2009; 28: 44-56.

3. Christensen G J. Computerized restorative dentistry. J Am Dent Assoc 2001; 132: 1301-3.

4. Mehl A, Hickel R. Current State of Development and Perspective of Machine Based Production Methods for Dental Restorations. Int J Comput Dent 1999; 2: 9-35.

5. Luthy $H$, Filser $F$, Loeffel $O$, Schumacher $M$, Gauckler LJ, Hammerle CHF. Strength and reliability of four-unit all-ceramic posterior bridges. Dent Mater.2005; 21: 930-7.

6. Reich $S$, Wichmann M, Nkenke $E$, Proeschel P. Clinical fit of all-ceramic threeunit fixed partial dentures, generated with three different CAD/CAM systems. Eur J Oral Sci. 2005; 113: 174-9.

7. Witkowski S, Komine F, Gerds T. Marginal accuracy of titanium copings fabricated by casting and CAD/CAM techniques. J Prosthet Dent 2006; 96: 47-52.

8. 8).Webber B, McDonald A, Knowles J. An in vitro study of the compressive load at fracture of Procera AllCeram crowns with varying thickness of veneer porcelain. J Prosthet Dent 2003; 89: 154-60.

9. Reiss B. Cerec standard 3-D occlusal contouring in comparison with the new biogeneric occlusal morphing: a case report. Int J Comput Dent 2007; 10: 69-75.

10. Quante K, Quintas AF, Oliveira F, Bottino MA. Vertical marginal discrepancy of ceramic copings with different ceramic materials, finish lines, and luting agents: an in vitro evaluation. J Prosthet Dent 2004; 92: 250-7.

11. Tinschert J, Natt G, Hassenpflug S, Spiekermann $\mathrm{H}$. Status of current CAD/CAM technology in dental medicine. Int J Comput Dent 2004; 7: 2545.

12. Santos EC, Shiomi M, Osakada K, Laoui T. Rapid manufacturing of metal components by laser forming. Int J Mach Tools Manuf 2006; 46: 145968.

13. Delikanlı K, Sofu M, Bekci U. Üretim sektöründe hızlı direkt imalat sistemlerinin yeri ve önemi. MTED 2005; 4: 33-9.

14. Azari A, Nikzad S. The evolution of rapid prototyping in dentistry: a review. Rapid Prototyping J 2009; 15: 216-25. 
15. Özuğur B. Hızlı Prototipleme Teknikleri ile Kompleks Yapıdaki Parçaların Üretilebilirliklerinin Araştırılması. Gazi Üniversitesi en Bilimleri Enstitüsü.Yüksek Lisans Tezi, 2006, Ankara, (Danışman: Yard. Doç. Dr. İhsan Korkut).

16. Uysal H. Hızlı Prototip Üretimi. Yıldız Teknik Üniversitesi, Makine Mühendisliği Anabilimdalı İmal Usulleri Programı. Yüksek Lisans Tezi, 2000,İstanbul, (Danışman: Prof. Dr. Erhan Altan).

17. Sundar MJ, Chikmagalur SB, Pasha F. Marginal fit and microleakage of cast and metal laser sintered copings-An in vitro study. J Prosthodont Res. 2014; 58: 252-8.

18. Shokry TE, Attia M, Mosleh I, Elhosary M, Hamza $T$, Shen $C$. Effect of metal selection and porcelain firing on the marginal accuracy of titanium-based metal ceramic restorations. J Prosthet Dent 2010; 103: 45-52.

19. Harish V, Mohamed Ali SA, Jagadesan N, Mohamed I, Siva S, Debasish B, Febel H. Evaluation of Internal and Marginal Fit of Two Metal Ceramic System - In Vitro Study. J Clin Diagn Res 2014; 8: 53-6.

20. Xu D, Xiang N, Wei B. The marginal fit of selective laser melting fabricated metal crowns: an in vitro study. J Prosthet Dent 2014; 112: 1437-40.

21. Huang Z, Zhang L, Zhu J, Zhang X. Clinical marginal crowns fabricated with a selective laser melting technology. J Prosthet Dent 2015; 113: 623-7.

22. Patil A, Singh K, Sahoo S, Suvarna S, Kumar P, Singh A. Comparative assessment of marginal accuracy of grade II titanium and $\mathrm{Ni}-\mathrm{Cr}$ alloy before and after ceramic firing: An in vitro study. Eur J Dent 2013; 7: 272-7.

23. Kim KB, Kim JH, Kim WC, Kim HY, Kim JH. Evaluation of the marginal and internal gap of metal-ceramic crown fabricated with a selective laser sintering technology: two- and threedimensional replica techniques.J Adv Prosthodont 2013; 5: 179-86.

24. Park JK, Kim HY, Kim WC, Kim JH. Accuracy evaluation of metal copings fabricated by computer-aided milling and direct metal laser sintering systems. J Adv Prosthodont 2015; 7: 122-8.
25. Ucar $Y$, Akova $T$, Akyil MS, Brantley WA. Internal fit evaluation of crowns prepared using a new dental crown fabrication technique: lasersintered Co-Cr crowns. J Prosthet Dent 2009; 102: 253-9.

26. Örtorp $A$, Jönsson $D$, Mouhsen $A$, von Steyern PV. The fit of cobalt- chromium three-unit fixed dental prostheses fabricated with four different techniques: A comparative in vitro study. Dent Mater 2011; 27: 356-63.

27. Kim KB, Kim WC, Kim HY, Kim JH. An evaluation of marginal fit of three-unit fixed dental prostheses fabricated by direct metal laser sintering system. Dent Mater. 2013; 29: 91-6.

28. Nesse $H$, Ulstein DM, Vaage MM, Qilo M. Internal and marginal fit of cobaltchromium fixed dental prostheses fabricated with 3 different techniques. J Prosthet Dent 2015; 114: 686-92.

\section{Yazışma Adresi}

Dr. Ş. Begüm Türker

Marmara Üniversitesi

Diş Hekimliği Fakültesi

34854 Başıbüyük, Maltepe

İstanbul, Türkiye

Tel: 02164121621 (1777)

Fax: 02164210291

e-mail: begumturker@hotmail.com 